\title{
Industrias óseas del paleolítico y postpaleolítico pirenaico en relación con los nuevos hallazgos de Jarama II (Guadalajara) *
}

\author{
Gema adán Álvarez **

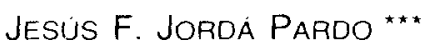

\section{INTRODUCCIÓN}

El yacimiento Jarama II se encuentra situado en el extremo noroccidental de la provincia de Guadalajara, término municipal de Valdesotos, en la margen izquierda del río Jarama, a $940 \mathrm{~m}$ sobre el nivel del mar, dentro de la hoja número 485 del Mapa topográfico Nacional a escala 1:50.000. Es una pequeña cavidad cárstica desarrollada en las calizas cretácicas de la zona a la que se accede por una abertura situada en la pared vertical del acantilado o farallón formado por el encajamiento del rio, descendiendo unos $5 \mathrm{~m}$ desde la superficie topográfica superior. En la entrada, orientada al $\mathrm{N}$, existe una pequeña cornisa a $22 \mathrm{~m}$ del suelo en caida vertical desde la que se puede pasar directamente al espacio subterráneo. El recorrido de la cueva es longitudinal, con un eje en dirección NS y una longitud reconocible de $10 \mathrm{~m}$ mientras que la anchura oscila entre $4 \mathrm{~m}$ y $1 \mathrm{~m}$, y la altura no supera los $2,5 \mathrm{~m}$, alcanzando en

- Trabajo presentado al "Congreso Internacional de Historia de los Pirineos, Cervera, $1988 \%$

* Gabinete Arqueológico. Oviedo.

..* Instituto Tecnológico Geo-Minero de España. Madrid. 
algunos puntos un minimo de $0,5 \mathrm{~m}$. El suelo de la cavidad antes de efectuar la excavación era practicamente horizontal, apareciendo constituido por un sedimento muy suelto y pulverulento, en el que se notaba la existencia de una pequeña cata realizada de manera irregular.

Después de efectuar unas prospecciones en 1983 bajo la dirección del Prof. Don F. Jordá Cerdá, procedimos a realizar una serie de excavaciones arqueológicas sistemáticas en el yacimiento Jarama II (1985 y 1988) bajo la dirección de uno de nosotros (J.F.J.P.) dentro del proyecto "Investigaciones Prehistóricas en el Alto Valle del Jarama", fruto de las cuales son los materiales óseos que presentamos en este trabajo, además de otros, tanto líticos y cerámicos como paleontológicos.

La secuencia estratigráfica obtenida a partir de estas excavaciones es bastante simple, y está integrada por tres niveles que de muro a techo son:

- Nivel detritico inferior, constituido por un conglomerado cementado de cantos de esquisto y cuarcita englobados por una matriz arenosa de color rojizo, esteril tanto arqueológica como paleontológicamente.

- Nivel detrítico medio, formado por limos y arenas muy sueltas, que a veces contiene cantos y bloques muy bien redondeados de cuarcita y esquisto, y que lateralmente hacia el exterior de la cavidad presenta una mayor compactación debido a la presencia de materia orgánica. En él hemos podido distinguir dos horizontes arqueológicos que veremos posteriormente.

- Corteza estalagmítica, que culmina el depósito y que se encuentra erosionada y eliminada en la practica totalidad del yacimiento, conservándose en algunos puntos adosada a las paredes. Contiene cantos y bloques muy bien redondeados de esquisto y cuarcita, asi como fragmentos cerámicos encostrados.

Dentro del nivel detrítico superior hemos podido distinguir dos horizontes arqueológicos. El más antiguo aparece distribuido principalmente por el interior de la cavidad y ocupa una posición inferior dentro de la estratigrafia, apareciendo generalmente removilizado y habiendose recuperado en él industrias líticas y óseas así como restos paleontológicos. El más reciente yace sobre el anterior en el interior de la cueva y alcanza un mayor desarrollo hacia la zona exterior, donde hemos podido dooumentar un enterramiento in situ. Entre los materiales aparecidos destacan las industrias líticas y óseas, las cerámicas, que se encuentran practicamente completas, y los restos óseos, entre los que señalaremos la pre- 
sencia de restos esqueléticos de al menos dos individuos, además de una abundante fauna de vertebrados.

El nivel más antiguo, como veremos posteriormente, puede atribuirse a un momento del Paleolítico Superior final, mientras que el horizonte superior corresponderá a un momento dentro del Calcolítico o de la Edad de Bronce.

El objeto de este trabajo es el estudio detallado de las industrias óseas (excluyendo los objetos de adorno en hueso) tanto paleolíticas como postpaleolíticas, aparecidas en las citadas excavaciones, para lograr determinar con mayor exactitud el momento cronológico al que pertenecen. Este objetivo adquiere una especial significación al haber aparecido en el yacimiento un pieza de Arte Mueble de excepcional interés, que fue extraida irregularmente, y que gracias a la industria ósea ha podido ser contextualizada (ver Jordá Pardo y García Valero en este mismo Congreso).

\section{METODOLOGIA}

La metodología aplicada al estudio de la industria ósea de Jarama II es similar a la utilizada y descrita por otros autores (Barandiarán, 1967; Camps-Fabrer, 1966, 1968; Camps-Fabrer, Bourrel y Nivelle, 1974; Corchón, 1981; Voruz, 1978), si bien, y debido a la diversidad de conceptos metodológicos, seguiremos unos criterios morfológicos abiertos, con los que ya hemos trabajado en anteriores ocasiones (Adán Álvarez, 1988, a y b).

Los criterios de orientación de las piezas, métricos y de denominación, con los que hemos realizado el presente estudio han sido definidos en los Coloquios que sobre industria ósea se han venido celebrando en los últimos años (ver Referencias, apartado Coloquios).

También prestamos especial atención a las técnicas de trabajo y elaboración (Camps-Fabrer, 1975; Semenov, 1981) que hemos podido distinguir en los útiles de Jarama $I I$, si bien no resulta fácil definir las técnicas de extracción y de elaboración de los objetos que constituyen la presente colección a partir de las huellas que aparecen en los instrumentos. Las primeras, que permiten fraccionar el bloque óseo, se suelen determinar en la mayor parte de los casos por deducción hipotética, lo 
que ocurre en nuestro caso, dado que los materiales de Jarama II no presentan matrices óseas que nos ayuden a determinar que procedimiento se ha seguido. Las técnicas de elaboración más visibles en el utillaje óseo, asimismo, pueden estar alteradas o enmascaradas por las huellas de uso, aunque su definición no resulta tan aventurada.

Las marcas o huellas de uso (Vozur, 1978), reconocibles de forma empírica, pueden marcar la pauta para intuir que un instrumento oseo fue utilizado, aunque no presente otras técnicas de trabajo.

Sobre la decoración, apreciable sólo en el instrumental paleolítico de la colección estudiada, no hemos profundizado excesivamentem debido a la existencia de concreciones calcáreas en algunas piezas que por el momento no han podido ser convenientemente eliminadas, si bien hemos seguido las clasificaciones mas usuales a este respecto (Barandiarán, 1967, 1981; Corchón, 1971, 1986).

Los estudios sobre industria ósea siguen mayoritariamente presupuestos tipológicos basados en la morfologia del útil, de forma que describiendo morfológicamente el objeto se suele acabar inevitablemente obteniendo datos funcionales. Como hemos mencionado, preferimos estudiar el material óseo desde un punto de vista morfológico, sin adentrarnos en conclusiones funcionales deducibles a partir de la forma. Estas son todavía demasiado intuitivas, sin que por el momento se hayan contrastado con más datos clarificadores (contexto arqueológicos, reconstrucciones experimentales, etc).

\section{LA INDUSTRIA ÓSEA DE JARAMA ॥}

\subsection{Descripción de las piezas}

Las excavaciones en el yacimiento Jarama II han aportado una colección de útiles óseos constituida por diez objetos, de los cuales cuatro pertenecen al horizonte del Paleolítico Superior, mientras que seis corresponden al horizonte postpaleolitico. A continuación describimos las piezas que componen la colección agrupándolas según el contexto al que pertenecen.

Industria ósea paleolítica: 
- Garra (fig. 1, 1; cuadro 1, n. ${ }^{\circ}$ 1). Pieza utilizada perteneciente a una garra de ave, en cuya parte mesial es posible identificar huellas de uso debidas, lo mas probable, a una suspensión realizada por esa zona del objeto óseo.

- Azagaya (fig. 1, 2; cuadro 1, n. ${ }^{\circ}$ 2). Útil obtenido mediante el ranurado de un asta de ciervo. La extremidad distal se consiguió por la abrasión de las cuatro caras que conforman una zona activa apuntada. La sección de la parte mesial es cuadrangular, faltándole a la pieza la parte y extremidad proximal. Presenta motivos decorativos en dos caras opuestas. En la cara superior un trazo longitudinal, cercano al borde derecho, con pequeñas líneas transversales situadas en la parte baja del útil. En la cara inferior la decoración es similar a la descrita, si bien la línea longitudinal se halla pegada al borde izquierdo y los trazos pequenos son transversales e inclinados, aunque situados en una zona idéntica a los de la cara superior.

- Azagaya (fig. 1, 3; cuadro $1, n{ }^{\circ} 3$ ). Objeto realizado sobre asta de ciervo, mediante las técnicas del ranurado, corte y abrasión del fragmento óseo. La extremidad distal se halla apuntada, el fuste es cilíndrico, recto, con una sección ovalada, y la extremidad proximal presenta un bisel. Se encuentra completa, si bien afectada parcialmente por concreciones carbonatadas muy delgadas, que necesitan ser eliminadas del útil con técnicas adecuadas para la visualización correcta del mismo, por lo que hasta el momento no podemos aportar más datos en cuanto a posibles decoraciones.

- Hueso apuntado (fig. 1,4; cuadro $1, n .^{\circ} 4$ ). Instrumento fabricado sobre una esquirla ósea obtenida a partir de la fragmentación longitudinal de la diáfisis de un hueso largo. Únicamente se transformó la zona activa mediante el corte de tres caras con lo que se obtuvo una extremidad apuntada.

Industria ósea postpaleolítica:

- Espátula (fig. 2, 5; cuadro 1, n. ${ }^{\circ}$ 5). Pieza fabricada sobre la diáfisis de una tibia de ovicáprido, que fue aserrada logitudinalmente separándola en dos, llegando una de las mitades a acondicionarse como útil. Una gran abrasión en su extremidad distal consigue borrar el canal medular. La extremidad proximal se halla fragmentada, aunque puede aventurarse una epífisis trabajada. Toda la pieza está pulimentada.

- Espátula (fig. 2, 7; cuadro 1, n. ${ }^{\circ}$ ). Útil realizado sobre esquirla ósea o costilla (?). Posee un gran aplanamiento con una cara inferior totalmente abrasionada. En la parte mesial de dicha cara observa un 
corte que da a la pieza un borde derecho afilado. La extremidad distal se halla fragmentada. Todo el instrumento ha sido intensamente pulimentado.

- Palita-espátula (fig. 2, 9; cuadro $1, \mathrm{n}^{\circ}$ 9). Objeto elaborado sobre una esquirla ósea alargada obtenida mediante ranurado, y con huellas de abrasión y pulimento sobre toda la pieza. El aspecto final es brillante, aplanado y con uno de sus bordes, el derecho, cortante. La extremidad proximal conforma una espátula.

- Punzón (fig. 3,6 ; cuadro $1, n .{ }^{\circ} 6$ ). Ha sido realizado sobre un metápodo de ovicáprido joven, el cual está aserrado longitudinalmente, eliminándose casi en su totalidad el canal medular. Con posterioridad se procedió al pulimento total de la pieza. La extremidad proximal presenta la epifisis pulida.

- Punzón (fig. 3,8 ; cuadro $1, n .{ }^{\circ} 8$ ). Instrumento trabajado sobre un metápodo de ovicáprido. Su morfología anatómica no fue alterada sustancialmente y sólo se aserró y abrasionó la extremidad distal para formar la parte activa, apuntada, del objeto. Esta zona tiene una longitud mayor de lo habitual al haberse afilado la extremidad y parte distal del punzón.

- Punzón (fig. 3, 10; cuadro 1, n. ${ }^{\circ} 10$ ). Útil obtenido mediante la separación en dos de una tibia de conejo (?), trabajándose una de las mitades hasta su transformación en útil. La zona activa está abrasionada $y$ pulida, ofreciendo una forma puntiaguda.

En el cuadro 1 se ofrecen las características de conservación de las piezas descritas junto a las medidas milimétricas de longitud y espesor de las partes distal, mesial y proximal y la morfología de las diferentes secciones.

\subsection{La industria ósea paleolítica}

De las cuatro piezas adscribibles a este período, tres pertenecen a la familia de los apuntados, siendo la cuarta pieza un objeto utilizado. Esta última es una garra de ave (fig. 1, 1) que presenta en su parte mesial huellas que pueden dar a entender una posible suspensión del objeto por la zona mencionada. Las marcas encontradas entrarian dentro de los caracteres secundarios definidos por Voruz (1978), más concretamente dentro de lo que él denomina esquirlado, que consiste en varios 


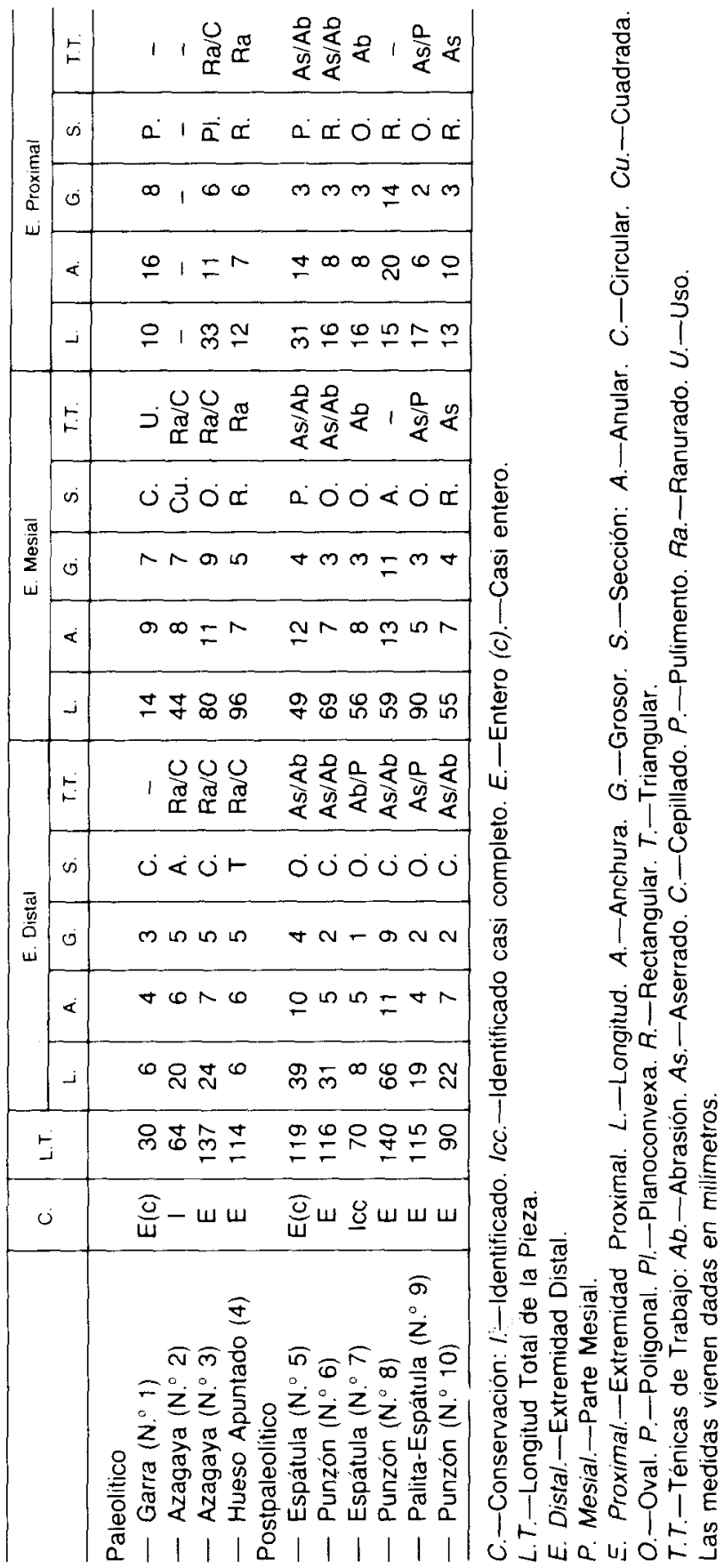



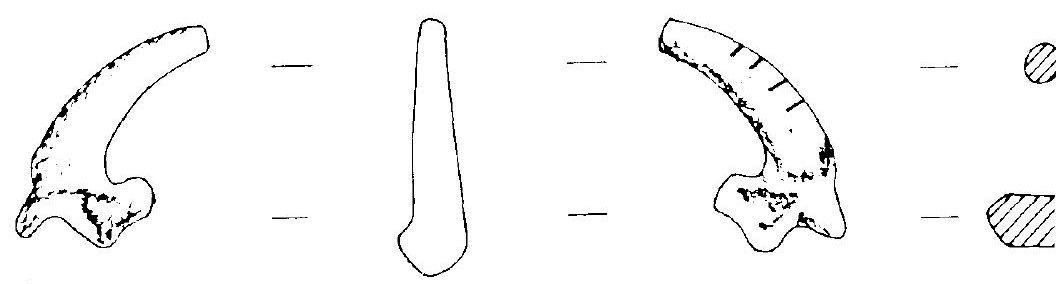

1
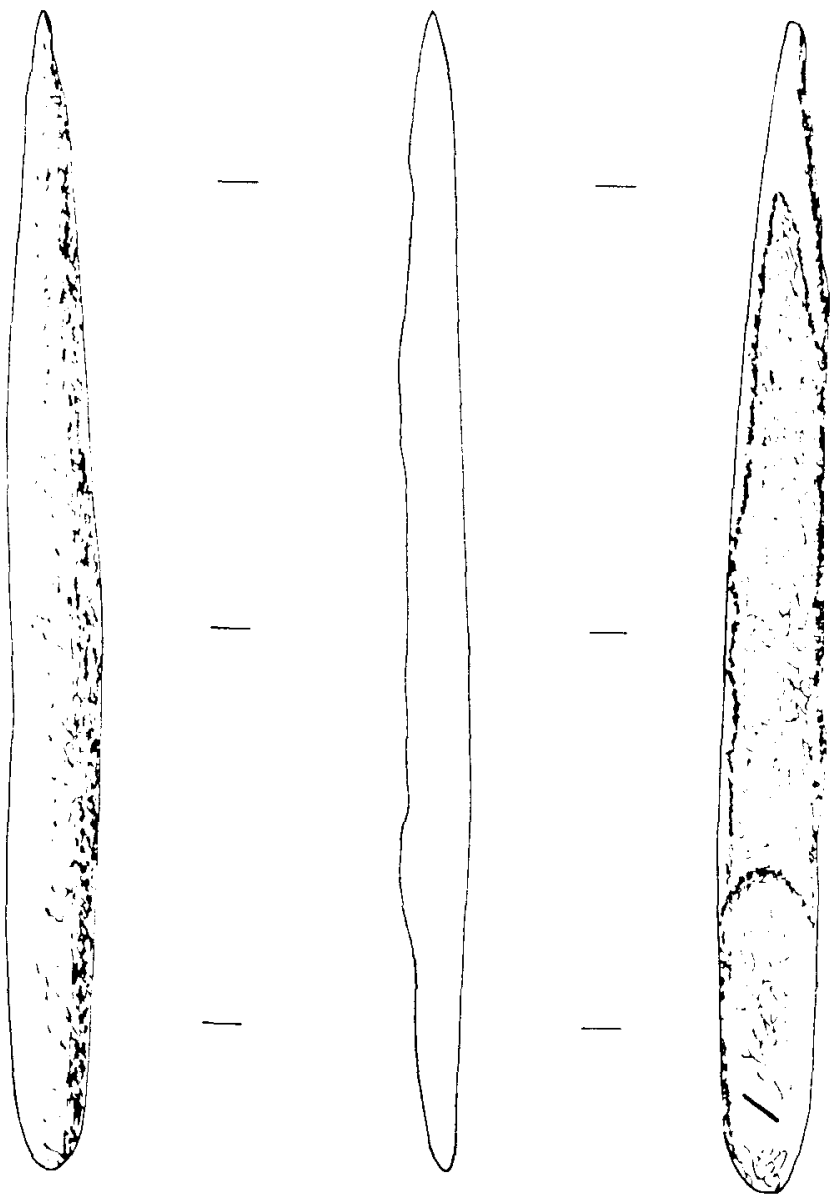

3

Fig. 1. Industria ósea paleolítica de Jarama 
Industrias óseas del paleolítico y postpaleolítico pirenaico en relación...
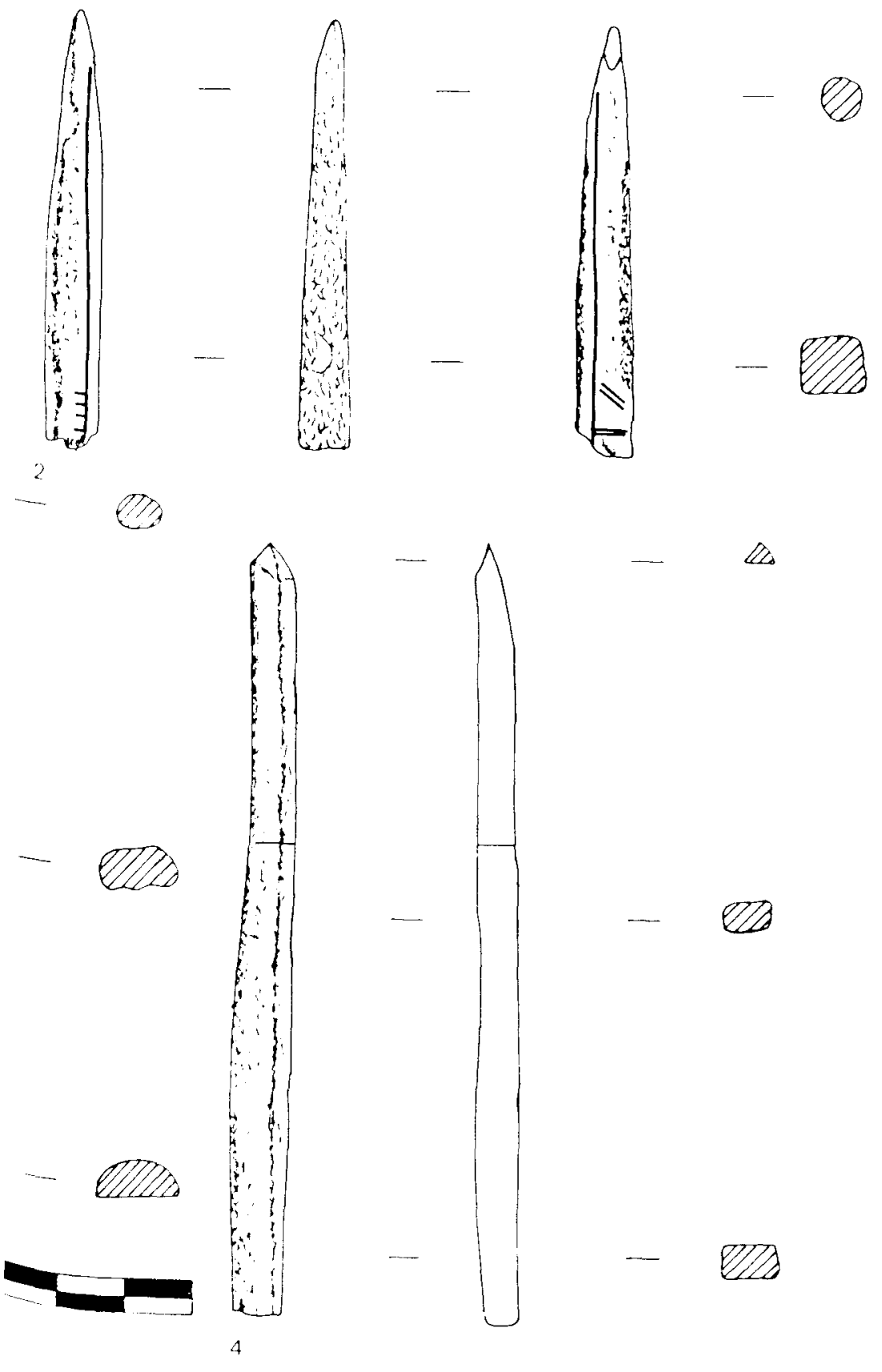

Ira de ave, 2 y 3 azagayas, 4 , hueso apuntado.

117 


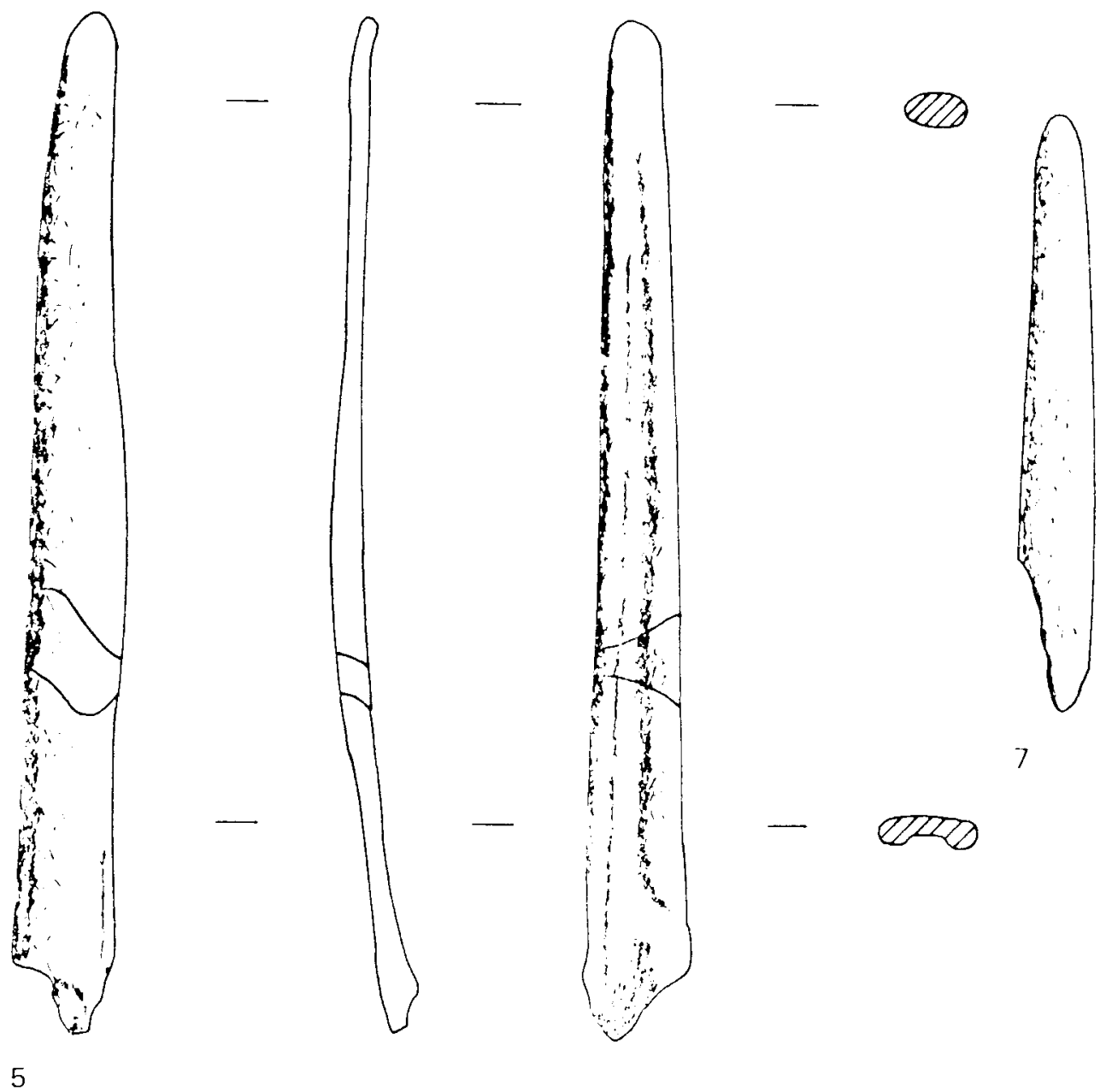

Fig. 2. Industria ósea postpaleolític 
Industrias óseas del paleolítico y postpaleolítico pirenaico en relación...

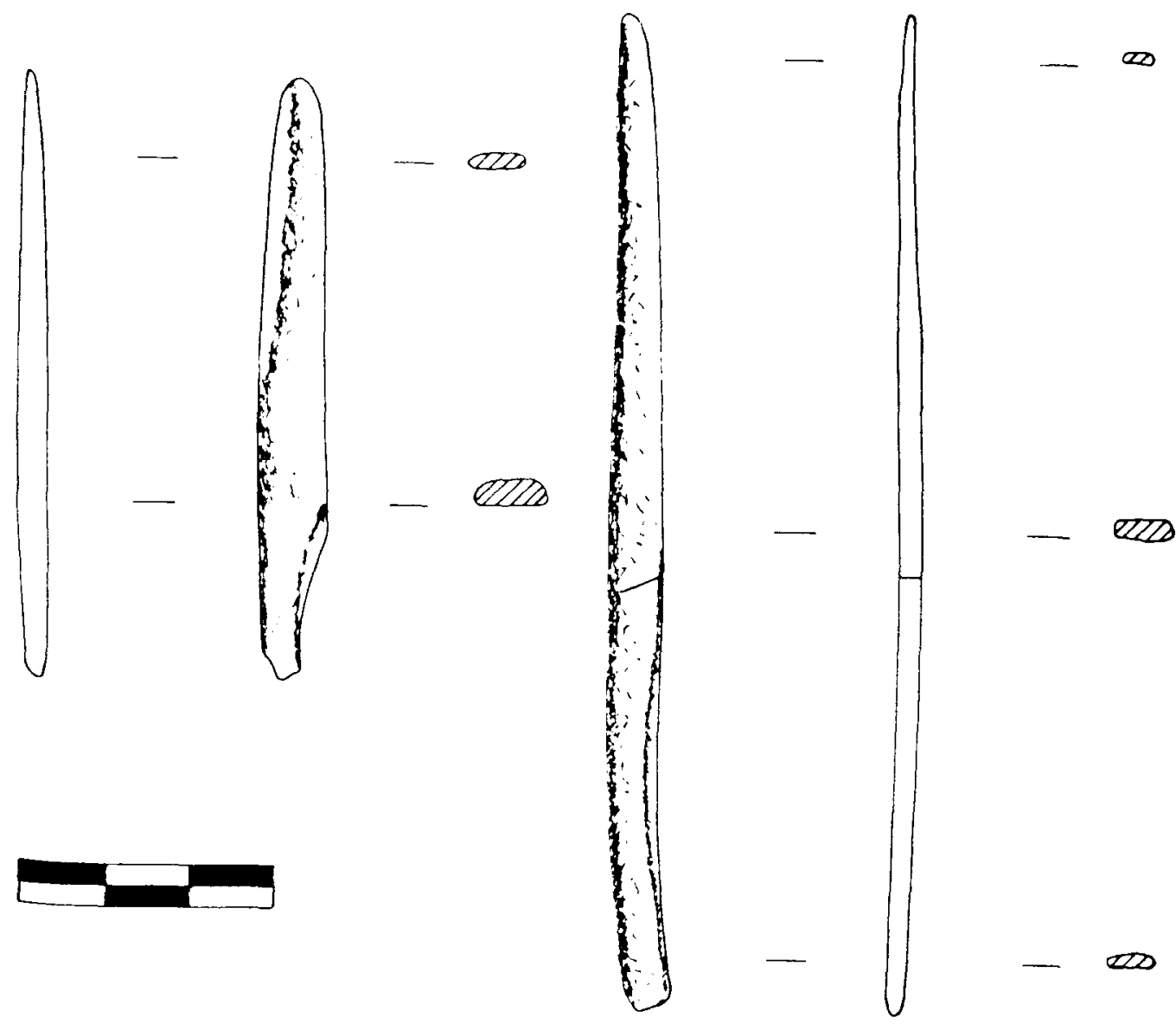

9

arama II: 5 y 7, espátulas, 9, palita-espátula. 


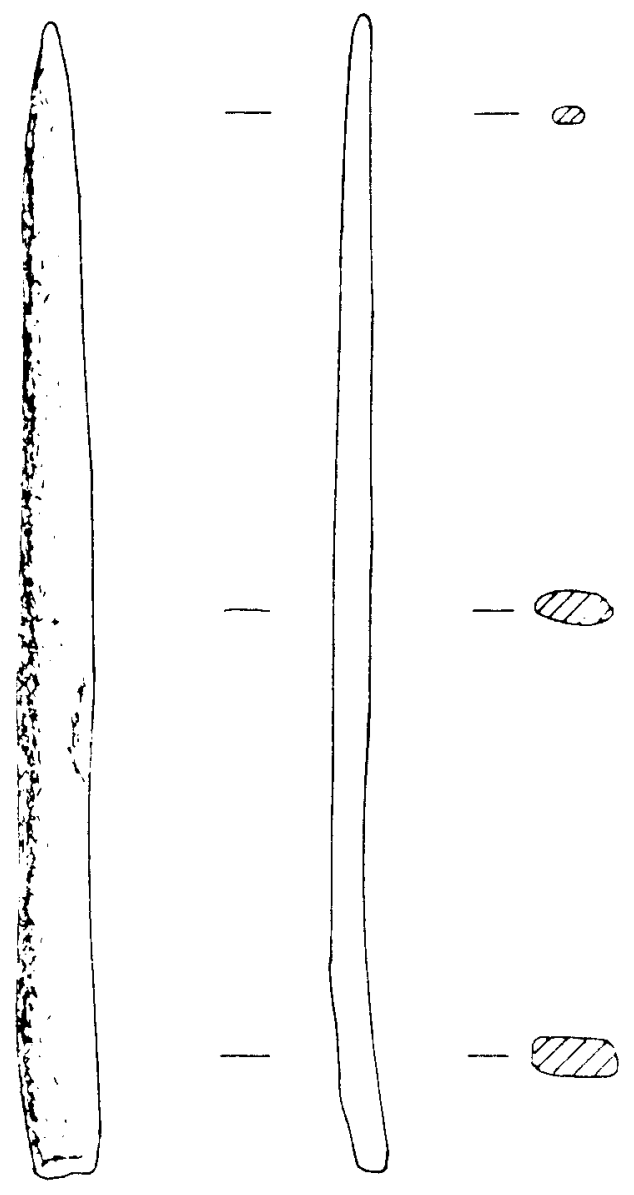

6
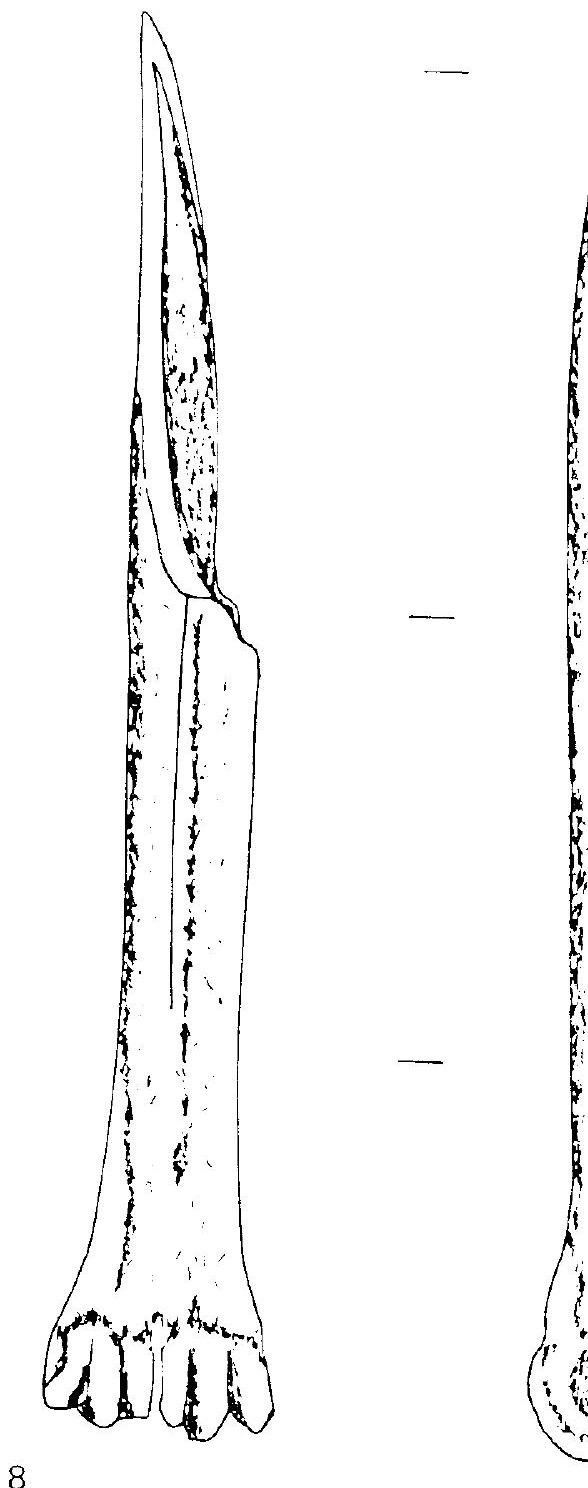

Fig. 3. Industria ósea pos 
Industrias óseas del paleolitico y postpaleolítico pirenaico en relación...
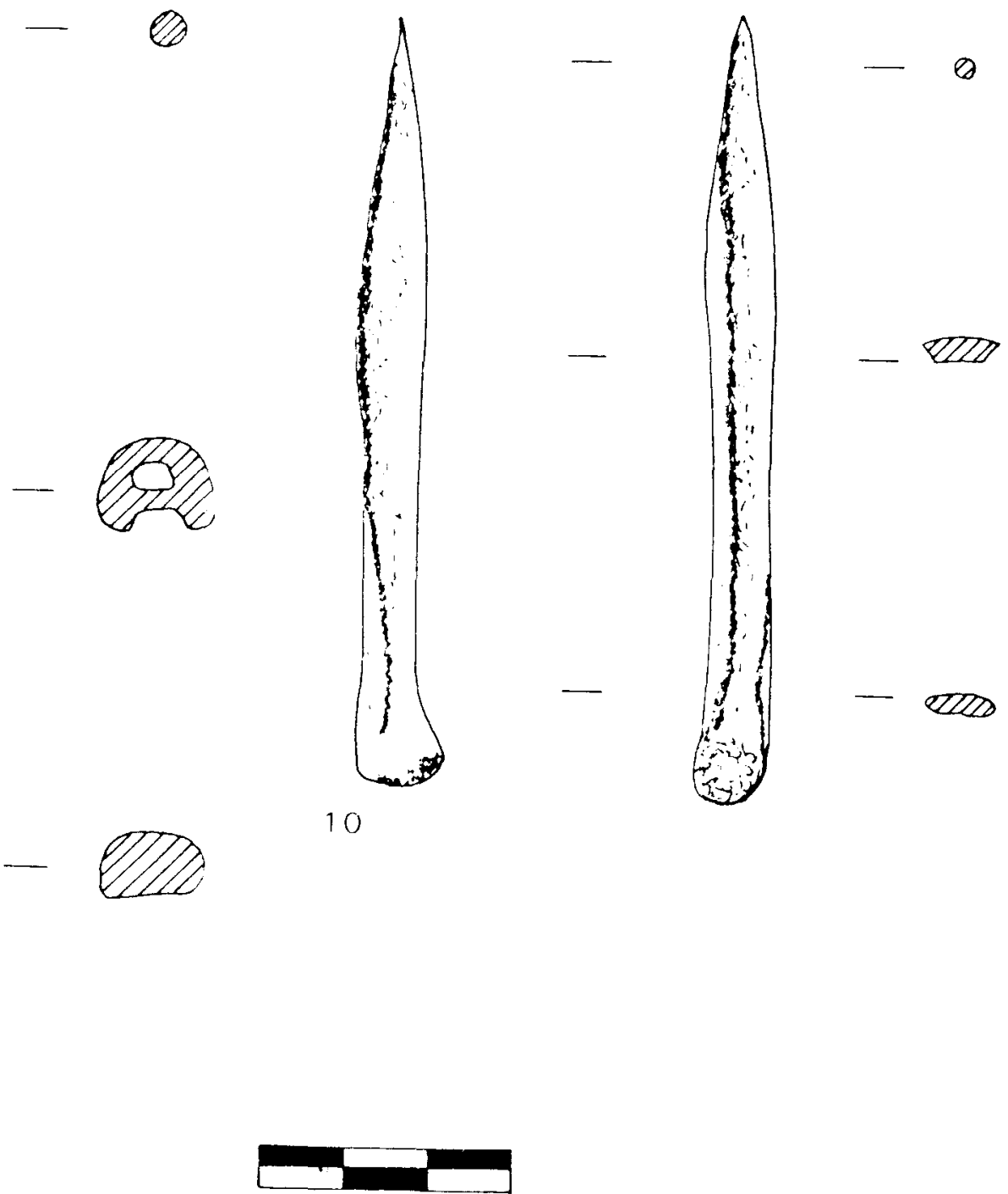

itica de Jarama II: punzones. 
levantamientos alargados y muy delgados, a menudo paralelos y escaleriformes, a veces superpuestos y yuxtapuestos.

De los tres objetos apuntados, dos se agrupan en el estado secundario de las azagayas, y el tercero entraría dentro de los que algunos autores denominan industria de hueso poco elaborado (Cabrera y Bernaldo de Quirós, 1978; Múgica, 1983), y que nosotros incluiremos en las industrias óseas, según los conceptos metodológicos empleados.

Las azagayas son claramente diferentes. La primera (fig. 1, 2), a la que le falta parte de la zona mesial y la extremidad proximal, presenta una sección cuadrangular con decoración en ambas caras. La segunda (fig. 1,3) se encuentra completa y alcanza los $137 \mathrm{~mm}$ de longitud total, con una parte mesial ovalada y extremidad proximal monobiselada. El estado actual de esta última pieza no permite apreciar ningún tipo de decoración, si bien se observa una incisión en el monobisel.

El hueso apuntado (fig. 1,4) es una esquirla ósea obtenida de un hueso largo, en la cual se modificó su extremidad distal con varios cortes en tres caras, consiguiendo asi el aguzamiento de la mencionada zona activa.

Las técnicas de extracción y elaboración, exceptuando el primer objeto en el que sólo se referencian huellas de uso, reflejan cierta complejidad propia de la época en que nos encontramos. Si bien las técnicas de extracción utilizadas son hipotéticas, al no haberse encontrado en el yacimiento matrices óseas, podemos considerar que fueron obtenidas mediante el ranurado, técnica de extracción empleada usualmente para la extracción de azagayas (Camps-Fabrer, 1975). Esta técnica, utilizada desde el Perigordiense, se complementa con el posterior corte y abrasión para la obtención de un útil perfectamente acabado. En el caso del hueso apuntado, despues del ranurado sólo se realizó el corte de la extremidad distal, sin mediar ninguna otra alteración morfológica de la pieza.

Los motivos decorativos encontrados en la azagaya de sección cuadrangular (fig. 1,2) estan presentes en ambas caras de la pieza, y como mas adelante se constatará, esta decoración se atribuye a un periodo determinado dentro de una zona concreta. La incisión visible en la azagaya de sección ovalada (fig. 1,3 ) se debe más a la manufactura del soporte o a la operatividad del útil que a posibles manifestaciones artísticas (Corchón, 1986). 


\subsection{La industria ósea postpaleolítica}

Este conjunto esta integrado por seis piezas óseas que pueden agruparse en dos familias diferentes; la de los objetos apuntados ( 3 piezas) y la de los objetos romos (3 piezas).

Dentro de los útiles apuntados es el apartado de los punzones el único que se encuentra representado, presentando los tres punzones aparecidos características morfológicas diferentes. Mientras dos de ellos (fig. 3, 6 y 10) son mitades de hueso largo con la extremidad distal apuntada, el tercero (fig. 3, 8) es un metápodo de ovicáprido entero al que le fue practicado un aserramiento lateral (borde derecho) en su distum anatómico.

Los tres útiles romos se agrupan en dos apartados, el de las espátulas ( 2 piezas) y el de las palitas ( 1 pieza), si bien esta última pieza es doble, y presenta una extremidad proximal adscribible a una espátula.

En la fabricación de las espátulas (fig. 2, 5 y 7) se siguieron procesos diversos. En la primera pieza se consigue el aplanamiento mediante una intensa abrasión producida en su cara interna, y en la segunda es su morfología anatómica la que proporciona la planitud requerida. De esta última (fig. 2,7 ) conviene destacar el rebaje efectuado en su cara interna cercano al borde izquierdo, que dota a la pieza de un filo cortante.

La pieza doble, considerada como palita - espátula (fig. 2, 9), presenta un perfil derecho cortante y aplanado debido a su fabricación, y un frente distal romo. La extremidad proximal, por el contrario, esta aplanada y roma por todos sus lados, diferenciándose claramente de lo que es la extremidad distal. Toda la pieza está ejecutada con gran cuidado y aparece enteramente pulida.

Las técnicas de fabricación utilizadas son el aserramiento y la abrasión. El primero para conseguir separar mitades y conformar las extremidades distales, mientras que la abrasión, realizada en un estadio posterior, consigue dar a la pieza una regularidad y un perfecto acabado. También para alcanzar este resultado se suele recurrir al pulimento de objeto óseo.

En estos objetos óseos, como es frecuente en los tiempos postpaleolíticos, la decoración sobre el soporte óseo se encuentra ausente. 


\section{ENSAYO CRONOLÓGICO}

A la vista de lo expuesto en el desarrollo del trabajo podemos extraer una serie de conclusiones a cerca del contexto cronológico al que pertenecen las piezas, su ámbito y las similitudes que reflejan en comparación con otras industrias óseas cercanas. No obstante, en cuanto a las precisiones cronológicas se refiere, podremos llegar a una mejor definición cuando se terminen de realizar los estudios sobre las industrias líticas y las cerámicas recuperadas en Jarama II, que pronto se daran a conocer en una completa monografía sobre el citado yacimiento.

La gran importancia que desde Breuil se ha concedido a los llamados "fósiles directores" a la hora de definir los diversos estadios o niveles del Magdaleniense, esta siendo motivo constante de controversia entre los investigadores. Pero, en última instancia y despues de la revisión de la problemática del Magdaleniense Inferior y Medio, elaborada por Utrilla (1981), se siguen utilizando la industria ósea para marcar las diferentes etapas en que se divide el Magdaleniense.

Las azagayas de sección cuadrangular, como la aquí estudiada, se situan dentro de la facies tipo Juyo del Magdaleniense Inferior Cantábrico (Utrilla, 1981). La decoración efectuada sobre ella, consistente en una representación no figurada caracterizada por su disposición longitudinal geométrica y desarrollada en torno a un eje perfectamente vertical (Corchón, 1986), también es propia de este momento.

La otra azagaya también entra dentro del utillaje del Magdaleniense Inferior Cantábrico, y según la nueva revisión efectuada por Corchón (1986) sería este tipo de azagaya, esbelta, de fuste cilíndrico, base con uno o dos biseles estriados oblicuamente y a veces con fuste acanalado, el tipo mas caracteristico de este Magdaleniense Inferior.

Asi pues, nos encontramos con una industria paleolítica típica del Magdaleniense Inferior (Magdaleniense III Cantábrico, tipo Juyo), con claros paralelos en yacimientos de la cornisa cantábrica como el Juyo (Barandiarán, 1985), el nivel 4 de Rascaño (González Echegaray y Barandiarán, 1981), el nivel IV de Ekain (Baldeón, 1984), el nivel 8 de la Cueva del Castillo (Cabrera Valdés, 1984), el nivel 4 del Cierro, el nivel D de Cueto de la Mina, las cuevas de La Riera y Balmori y la parte superior de la estratigrafía de Altamira (Corchón, 1986).

El instrumental óseo postpaleolítico cambia radicalmente el panorama reflejado con anterioridad. Los útiles se fabrican sobre especies 
domesticadas y las técnicas de trabajo y elaboración alteran lo menos posible la morfologia anatómica ósea. Incluso se eligen zonas óseas que tienden a parecerse a las características buscadas por el artesano, como por ejemplo, para conseguir la planitud de las espátulas se elige como materia prima las costillas de los diferentes animales.

Para la realización de los instrumentos punzantes se sigue prefiriendo el material óseo, que también parece tener buenas peculiaridades en la fabricación de objetos romos y aplanados. Cuando con el tiempo se encuentre otro material que aune las singularidades que posee el hueso, junto con la dureza de la piedra, como es el metal, la cantidad de instrumentos óseos disminuirá, y su utilización se deberá a otro tipo de prioridades completamente diferentes a las manejadas hasta el Calcolitico.

A nivel cronológico, no ocurre en estos períodos holocenos como en los precedentes, y aqui no se cuenta con "fósiles directores", que delimiten los diversos estadios culturales.

No obstante, intentaremos hacer una tentativa cronológica para estos materiales postpaleolíticos que componen el resto de la colección de Jarama II, y que en principio son adscribibles en una primera aproximación a los tiempos del Calcolítico o a los inicios de la Edad del Bronce (Jordá Pardo, 1986). La industria ósea aquí tratada puede encuadrarse en cualquiera de los dos períodos, pero es sobre todo el punzón sobre metápodo de ovicáprido (fig. 3,8 ) el que nos inclina a incluir estos materiales dentro del Calcolítico, manteniendo todas las reservas posibles debido a la ausencia de "fósiles guía" en estas etapas.

Si en un principio los metápodos de ovicápridos se transformaban en punzones desplegando un gran cúmulo de técnicas (Murray, 1979), en épocas finales del Neolítico y en el Calcolítico, la forma más frecuente de trabajar esta parte anatómica es con el simple corte frontal o lateral del distum, sin alterar el resto de la pieza. Todo esto se engloba dentro de un proceso más general que empezando en el Neolitico final culmina con la aparición de los metales, y, si bien se continuan una serie de tipos esenciales (punzones, agujas, etc.), se produce una gran tosquedad, con una parquedad en el uso de técnicas de trabajo y un empobrecimiento del utillaje óseo.

Esta evolución se constata tanto en yacimientos franceses (CampsFabrer, 1975; Camps-Fabrer y Roudil, 1982; Camps-Fabrer y Paccard, 1985) como españoles (Adán Álvarez, 1988, b), por lo que se trata de un hecho generalizado en el ámbito geográfico situado a ambos lados de los Pirineos. 
Cronológicamente, a la vista de lo anterior, y en espera de nuevos datos con los que apoyar o refutar las consideraciones aquí expuestas, podemos incluir el instrumental óseo que compone la colección de Jarama II dentro de dos períodos culturales distantes y claramente diferenciados: el Magdaleniense Inferior y el Calcolítico, este último con más interrogantes que el primero.

\section{INTERPRETACIÓN}

Las peculiaridades del yacimiento Jarama II, descritas en apartados anteriores, y las características de los materiales aparecidos en él, nos permiten realizar unas consideraciones sobre la funcionalidad del citado yacimiento dentro de unos contextos cronológicos definidos.

Un hecho que destaca en este pequeño yacimiento es la existencia de la interesante colección de útiles óseos de los períodos reseñados, la mayoría en un buen estado de conservación, prácticamente completos. A esto hay que unir la presencia de algunos útiles líticos acabados, la ausencia de restos de talla, la aparición de cerámicas prácticamente completas, la existencia de numerosos restos óseos de animales, y sobre todo la aparición de restos humanos y de estructuras funerarias.

Del período Magdaleniense contamos con poca información debido fundamentalmente a las características del yacimiento y a la remoción efectuada en este por los ocupantes calcolíticos. No obstante, y como presentamos en otra comunicación en este Congreso, el hallazgo fundamental atribuible a este periodo es una estatuilla de marfil de bulto redondo que representa un glotón. Junto a esto contamos con restos de industrias líticas y con las piezas óseas estudiadas en este trabajo. Pese a las dificultades en la excavación, es posible reconocer restos antropológicos atribuibles a este período (actualmente en estudio). Todo ello nos hace pensar que la cueva tendría en esta etapa cronológica una funcionalidad ritual, posiblemente fúnebre, lo que no resulta difícil de suponer dadas las características de accesibilidad y habitabilidad con que cuenta la cueva. La ausencia de hogares y de restos de talla nos confirman esta hipótesis.

De forma más clara, también podemos atribuir la ocupación de la cueva en los tiempos calcolíticos a una función ritual, y en este caso claramente funeraria. La aparición de estructuras que delimitan un ente- 
rramiento de al menos dos individuos, provisto de un completo ajuar, asi lo confirman, junto con las características propias de la cueva señaladas líneas arriba.

Por tanto, y a la espera de los estudios que se están efectuando con los restantes materiales aparecidos, podemos afirmar que la cueva de Jarama II tuvo en los tiempos prehistóricos una finalidad ritual, de tipo funerario.

En cuanto a las relaciones de Jarama II con otros yacimientos, a la vista de los datos aportados por la industria ósea aquí estudiada, podemos señalar el paralelismo existente con los yacimientos cantábricos del Magdaleniense Inferior. Por otro lado, la pieza de arte mueble que representa un glotón se encuentra más relacionada con el ámbito pirenaico, a través de la Cueva de los Casares, en donde encontramos también una representación parietal de este mustélido.

Todo ellos nos lleva a plantear una hipótesis de trabajo que intentaremos verificar con futuras investigaciones, y que se articula en dos argumentos básicos. El primero se refiere a la posibilidad de que el Alto Valle del Jarama fuera una zona donde confluyeran las dos corrientes culturales, cantábrica y pirenaica, durante el Paleolítico Superior, y concretamente en el Magdaleniense. El segundo y más problemático, trataria de verificar, si la aparición de nuevos yacimientos lo permiten, el sentido del avance de las culturas magdalenienses (desde Francia a España, sentido clásico, o desde España a Francia, nuevas hipótesis) a través de la barrera montañosa de los Pirineos. 


\section{BIBLIOGRAFÍA}

Adán Álvarez, G., 1988: "La Industria ósea neolítica de la Cueva de Nerja (Sala de la Mina, 1979-1982)", Actas del Congreso Internacional El Estrecho de Gibraltar, Ceuta 1987, tomo I, Madrid. pág. 255270.

- 1988b: Industria ósea de la Cueva de Nerja (Malaga). Epipaleolítico, Neolítico y Calcolítico, Tesis de Lincenciatura, Oviedo.

BALDeón, A., 1984: “Industria ósea de Ekain», en Altuna, J. y Merino, J.M., El yacimiento prehistórico de la Cueva de Ekain (Deba, Guipúzcoa), San Sebastian. Editorial Eusko Iraskuntza, pág. 189-209.

Barandiarán, I., 1967: El Paleomesolítico del Pirineo Occidental. Bases para una sistematización tipológica del instrumental óseo Paleolítico, Monografías Arqueológicas, núm. 3, Zaragoza.

- 1985: “Industria ósea paleolitica de la Cueva del Juyo. Excavaciones de 1978 y 1979", en Barandiaran, I. et alii, Excavaciones en la Cueva del Juyo, Monografias del Centro de Investigación y Museo de Altamira, núm. 14, Santander, pág. 161-194.

Cabrera Valdes, V., 1984: El yacimiento de la Cueva de el Castillo (Puente Viesgo, Santander), Bibliotheca Praehistorica Hispana, vol. XXII, Madrid, 485 páginas.

Cabreta Valdés, V. y Bernaldo de Quirós, F., (1978): “Principio de estudio de la industria de hueso poco elaborado", Trabajos de Prehistoria, vol. 35, Madrid, pág. 45-60.

CAmps-FABreR, H., 1966: Matière et art mobilier dans la Préhistoire NordAfricanine et Saharienne, Paris, AMG.

- 1968: "Industrie osseuse epipaléolithique et néolithique du Magreb et du Sahara, Types 1-30", Fiches Typologiques Africaines, 6. Cahier, Fiches 167-199; Types 31-54, 7. Cahier, Fiches 220-225, Paris-Alger. 
- 1975: “Le travail de l'os au Paléolithique et au Mesolithique», Travaux de LAPEMO, Aix en Provence, pág. 1-8.

Camps-Fabrer, H. y RoudiL, J.L., 1982: “L'industrie osseuse du la Grotte de Combe Obscure (Lagorce, Ardeche)", Industrie de l'os néolithique et de l'Age des Metaux, 2, CNRS, París, pág.33-59.

CAMPS-FABRER, H. y PACCARD, M., 1985: “L'industrie osseuse de la Grotta d'Unang. Malemort-du-Comtat, Vaucluse", Industrie de l'os néolitihique et de l'Age des Metaux, 3, París, pág. 44-55.

ClotTES, J., 1976: "Les Civilisations du Paleolithique Superieur dans les Pyrénees", La Prehistoire Française, vol. I, 2, Paris, pág. 1214-1231.

CorChON, S., 1971: Notas en torno al Arte Mueble Asturiano, Colección Opera Minora del Seminario de Prehistoria y Arqueología de la Universidad de Salamanca, Salamanca, 58 páginas.

- 1981: La Cueva de las Caldas. San Juan de Priorio (Oviedo), EAE., núm. 115, Madrid, 268 páginas.

- 1986: El arte mueble Paleolítico Cantábrico: Contexto y análisis interno. Monografías del Centro de Investigación y Museo de Altamira núm. 16. Santander.

González Echegaray, J y Barandiarán Maestu, I., 1981: El Paleolítico Superior de la Cueva del Rascaño (Santander) Monografías del centro de Investigación y Museo de Altamira, núm 359, Santander, 359 páginas.

JORDÁ PARDO, J.F., 1986: "Jarama II. Nuevo yacimiento del Paleolítico Superior", Revista de Arqueología, núm 61, Madrid, pág. 14-24.

MúGICA, 1983: "La industria del hueso en la Prehistoria de Guipúzcoa», Munibe, núm! 35, San Sebastián, pág. 451-631.

Murray, C., 1979: "Les techniques de débitage de métapodes de petits rumiants à Auvenier-Port", Industrie de l'os néolithique de l'Age des Metaux, CNRS, Paris, pág. 27-35.

Semenov, SA., 1981: Tecnología Prehistórica, Ed. Ariel, Madrid.

UtRILlA, P., 1981: El Magdaleniense Inferior y Medio en la Costa Cantábrica, Monografias del Centro de Investigación y Museo de Altamira, núm. 4, Santander.

VorUz, J.L., 1978: "Typologie de l'industrie en matières dures animales. Essai d'extension de la typologie analityque. Première ètape. La Langage Descriptif», Dialektike, Coaraza, pág. 38-53.

\section{Coloquios}

(1974): Premier Colloque Internacional sur l'Industrie de l'os dans la Préhistoire. Direction H. Camps Fabrer, Editions de l'Université de Provence. 
(1976): Deuxième Colloque International de l'industrie de l'os dans la Préhistoire. Méthodologie Appliquée à l'Industrie de l'os préhistorique. Editions CNRS., París.

(1979): Industrie de l'os néolithique et de l'Age des Métaux. Première réunion du Groupe de Travail núm. 3 sur l'Industrie de l'os préhistorique. Editions CNRS., París.

(1982): Industrie de l'os néolithique et de l'Age des Métaux. Deuxième réunion du Groupe de Travail núm. 3 sur l'Industrie de l'os préhistorique. Editions CNRS., París.

(1985): Industrie de l'os néolithique et de l'Age des Métaux. Troisième réunion du Groupe de Travail núm. 3 sur líndustrie de l'os préhistorique. Editions CNRS., París. 